
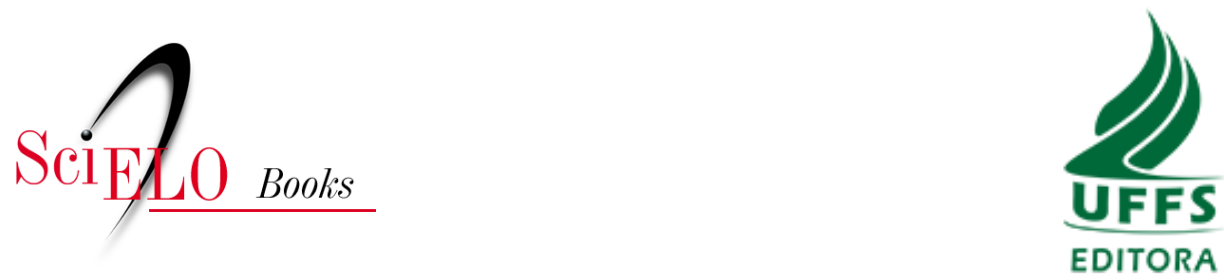

\title{
Políticas de democratização do acesso à educação superior e ações afirmativas
}

\author{
Rosileia Lucia Nierotka \\ Joviles Vitório Trevisol
}

\section{SciELO Books / SciELO Livros / SciELO Libros}

NIEROTKA, R.L., and TREVISOL, J.V. Políticas de democratização do acesso à educação superior e ações afirmativas. In: Ações afirmativas na educação superior: a experiência da Universidade Federal da Fronteira Sul [online]. Chapecó: Editora UFFS, 2019, pp. 40-64. ISBN: 978-655019-009-5. https://doi.org/10.7476/9786550190071.0003.

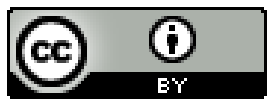

All the contents of this work, except where otherwise noted, is licensed under a Creative Commons Attribution 4.0 International license.

Todo o conteúdo deste trabalho, exceto quando houver ressalva, é publicado sob a licença Creative Commons Atribição 4.0. 


\section{POLÍTICAS DE DEMOCRATIZAÇÃO DO ACESSO À EDUCAÇÃO SUPERIOR E AÇÕES AFIRMATIVAS}

Que o futuro nos traga dias melhores e a capacidade de construir a Universidade que está nos nossos corações, nas nossas mentes e nas necessidades do povo brasileiro.

Florestan Fernandes

Este capítulo apresenta um panorama sobre o Estado e a política educacional na área da educação superior, a partir da década de 1990, sob a influência neoliberal. Em seguida, enfatiza as políticas relacionadas à democratização do acesso à educação superior que foram sendo desenvolvidas num contexto mais recente, principalmente a partir da primeira década dos anos 2000, nos governos de Lula e Dilma. O capítulo explora, também, uma trajetória das ações afirmativas como políticas de acesso à educação superior pública, as quais foram sendo implementadas pelas universidades, o que culminou com a aprovação da "Lei das Cotas", em 2012.

\section{ESTADO E POLÍTICAS DE EDUCAÇÃO SUPERIOR}

As políticas educacionais brasileiras, principalmente a partir dos anos 90 do século passado, foram fortemente influenciadas pela lógica da globalização neoliberal. Nessa perspectiva, os objetivos econômicos 
se sobrepuseram aos ideários da emancipação, e a produção do conhecimento se pautou pela lógica competitiva (LIBÂNEO, 2012).

Chauí (1999) observa que houve uma mudança, a partir da década de 1970, na forma de acumulação do capital, passando para um modelo de acumulação flexível. O Estado deixa de ser, progressivamente, o agente central de regulação do mercado e garantidor dos direitos sociais, para assumir a função de gerente e fiscalizador. $\mathrm{O}$ mercado assume-se como regulador de si mesmo, dispensando a presença estatal. Nesse sentido, “[...] a ideia de direitos sociais ou políticos tende a desaparecer, porque o que era um direito converte-se num serviço privado regulado pelo mercado e, portanto, torna-se uma mercadoria a que tem acesso apenas os que têm poder aquisitivo para adquiri-la" (CHAUÍ, 1999, p. 31).

De acordo com a autora, o neoliberalismo se apresenta como uma ideologia de pensamento único, tendo como seu subproduto o ideário pós-moderno, que concebe a realidade como "[...] a fragmentação econômico-social e a compreensão espaço-temporal gerada pelas novas tecnologias e pelo percurso do capital financeiro. [...] corresponde a uma forma de vida determinada pela insegurança e violência institucionalizada pelo mercado" (CHAUÍ, 1999, p. 33). Diante dessa nova forma de acumulação do capital, a mão-de-obra torna-se cada vez mais obsoleta, e o desemprego assume uma dimensão estrutural. Há um aumento das terceirizações e das privatizações; o capital financeiro e o monetarismo tornam-se o centro do capitalismo.

Diante desse contexto, conforme enfatiza Lima (2012), a educação é menos um bem público e mais um serviço, um bem privado a ser vendido. O autor descreve esse contexto como a "sociedade da aprendizagem", em que a educação é reduzida a uma dimensão utilitarista, deixando de lado seu caráter mais crítico, transformador, o "seu compromisso com o aperfeiçoamento humano, com o aprofundamento da democracia, com as demandas de justiça e de cidadania ativa" (LIMA, 2012, p. 15). 
Sennett (2013) caracteriza esse contexto como uma "cultura do novo capitalismo", que introduz novos valores aos sujeitos, baseados na individualização, na capacitação e eficiência para se tornar mais competitivo. Trata-se da passagem do capitalismo industrial para uma forma de acumulação capitalista, baseada em relações mais flexíveis. O autor usa uma metáfora para contextualizar essa mudança, em que se partiu da "jaula de ferro", na qual os trabalhadores planejavam suas carreiras por longo prazo e se passou para o "Mp3", em que as relações produtivas são pensadas em curto prazo, sendo flexíveis e maleáveis.

Essa nova cultura apontada por Sennett (2013), que perpassa várias dimensões da vida social, desafia a pensar a educação nessa sociedade conhecida como das "capacitações", sendo o conhecimento visto não mais como um bem durável, mas como algo flexível, em que é preciso aprender cada vez mais para competir.

A esse respeito, Libâneo (2012) oferece contribuições para entender a educação brasileira à luz da influência de órgãos internacionais e uma perspectiva dualista da escola pública, caracterizada como uma escola do conhecimento para os ricos e do acolhimento social para os pobres. Esse dualismo, que mantém e reproduz as desigualdades sociais, tem vínculos com os acordos internacionais, a partir da Conferência Mundial sobre Educação para Todos, realizada em Jomtien, na Tailândia, em 1990, sob os auspícios do Banco Mundial, do Programa das Nações Unidas para o Desenvolvimento (PNUD), do Fundo das Nações Unidas para a Infância (UNICEF) e da Organização das Nações Unidas para a Educação, a Ciência e a Cultura (UNESCO).

Essa Conferência produziu o documento Declaração Mundial sobre Educação para Todos: satisfação das necessidades básicas de aprendizagem. No âmbito brasileiro, essa conjuntura influenciou diretamente as políticas educacionais nas últimas décadas. Um primeiro documento, após essa Conferência, foi o Plano Decenal de Educação para Todos (1993-2003), elaborado durante o Governo Itamar Franco. O conteúdo influenciou as 
políticas e diretrizes para a educação dos governos de Fernando Henrique Cardoso e de Luiz Inácio Lula da Silva, tais como: universalização do acesso escolar, repasse de recursos financeiros, financiamento, descentralização da gestão, ensino a distância, sistema nacional de avaliação, Parâmetros Curriculares Nacionais, LDB etc. (LIBÂNEO, 2012).

$\mathrm{O}$ autor argumenta que as políticas educacionais do Banco Mundial para os países em desenvolvimento e os traços da escola dualista representam explicações para o incessante declínio da escola pública brasileira nos últimos 30 anos. O debate destaca o impacto negativo da influência dos organismos internacionais na educação brasileira, pois foi transformando em cartilhas a elaboração de planos de educação dos governos federal, estadual e municipal, afetando a formação de professores, as formas de financiamento, as formas de currículo, as práticas de avaliação e a organização da escola.

Lima (2012) também destaca que existe hoje um "pedagogismo" dominante, que reforça a tese de que por meio da educação são possíveis grandes mudanças sociais e econômicas. Em documentos da União Europeia, essa concepção é visível quando se fazem alusões à ideia de prosperidade na economia global acessível a todos. As universidades encontram-se cada vez mais ligadas ao mundo empresarial e sua geração de conhecimento voltada para a comercialização.

Destacam-se as profundas alterações no campo das decisões políticas em educação, na relação entre estado e sociedade civil, principalmente no contexto europeu. Com o surgimento de novas instâncias supranacionais, agendas globais alteram a relação tradicional de educação, estado e sociedade civil. Há um deslocamento da concepção de educação para a centralidade na aprendizagem individual, voltada para obter ganhos econômicos e aumento da produtividade (LIMA, 2012).

Nessa mesma direção, Dale (2004) analisa as políticas educacionais no contexto de uma agenda globalmente estruturada, em que o Estado é influenciado por organismos internacionais, a exemplo da UNESCO. Os países precisam manter-se competitivos e seguem essa lógica da 
globalização, movida por interesses econômicos, para garantir também seus financiamentos.

Nesse contexto neoliberal, o Estado assume novas formas de regulação e se transforma na condição de avaliador para estabelecer metas de desempenho e distribuir seus recursos ao longo das Instituições, ou seja, sai de uma lógica de administrador das políticas passando para uma instância da gestão. E, a partir dos anos 1990, constata-se a posição de um Estado mínimo para as políticas públicas, com a marca das privatizações e a distribuição de um conjunto de suas funções para outras instâncias da sociedade civil, na ótica da competitividade e o do individualismo (DALE, 2004).

Cita-se aqui a ideia de uma sociedade performativa, cujo destaque, conforme Ball (2010), é a mercadorização do conhecimento para a competição, e essa lógica influencia diretamente o setor público da educação e da política social. Performatividade é definida como "[...] uma tecnologia, uma cultura e um modo de regulação, e mesmo, tal como define Lyotard, um sistema de 'terror', sistema que implica julgamento, comparação e exposição, tomados respectivamente como formas de controle, de atrito e de mudança" (BALL, 2010, p. 38). As performances tanto de organizações como de sujeitos individuais aparecem como medidas de qualidade, de resultados e de produtividade, e o conhecimento adquiriu um status de mercadoria, adquirindo um valor de troca.

Miranda (2005) também destaca alguns aspectos da educação na sociedade contemporânea, marcada por uma nova concepção de educação, ou seja, a escola constituída por um princípio de conhecimento estaria dando lugar ao princípio da "socialidade". A autora refere-se a esse princípio ao tratar da organização da escola por ciclos, que "situa como um tempo/espaço destinado à convivência dos alunos, à experiência da socialidade”. (2005, p. 641). Esse princípio implica muitas mudanças na organização escolar, uma vez que o conhecimento é relegado a um segundo plano, e o importante é a permanência na escola, a proteção dos riscos sociais e o desfrutar dela como um espaço de cidadania, de convivência, da formação de valores sociais. 
Libâneo (2012) dialoga nessa mesma perspectiva, ao afirmar a concepção de uma escola dualista e voltada para as aprendizagens mínimas, ou seja, uma visão de escola assentada no conhecimento e outra em missões sociais, tendo como pano de fundo a perspectiva da inclusão. Para continuar competindo no mercado mundial, o Brasil vem fomentando algumas iniciativas de inclusão com vistas a resolver sua dívida histórica de um contexto de desigualdades sociais e educacionais.

Severino (2008) ainda reforça a ideia de que para uma análise referente às políticas educacionais, o ponto de partida é situar o contexto da globalização da economia. Para ele, "[...] a problemática da educação superior brasileira não pode ser abordada sem se ter bem presente a consolidação do projeto societário capitalista neoliberal em nosso país, neste início de milênio" (SEVERINO, 2008, p. 76).

O capitalismo contemporâneo configurou uma sociabilidade típica, com base em profundas mudanças nas esferas do trabalho, da cultura e da cidadania. (SEVERINO, 2006). Trata-se de uma lógica perversa que compromete a humanização. No entanto, também faz a crítica quanto às reais condições para assegurar uma educação de qualidade. Observa, ainda, que o conhecimento se tornou um mero produto e não mais um processo. $\mathrm{O}$ autor aponta para a necessidade da construção de uma nova sociedade e uma nova sociabilidade e acredita na capacidade dos seres teleológicos e na educação para atuar como força de transformação, embora sua atuação tende a ser de conformação social. Considera que a educação precisa ser uma prática mediadora de forças emancipatórias, buscando uma humanidade mais renovada.

Ao analisar a educação superior, Chauí (2001, p. 112) descreve a universidade transformada num supermercado, definida como um espaço, em que "[...] estantes de produtos ocultam todo o trabalho que ali se encontra: o trabalho da fabricação, da distribuição, do arranjo, da colocação de preços". Na universidade supermercado, 
[...] entram os felizes consumidores, ignoram todo o trabalho contido numa aula, num seminário, numa dissertação, numa tese, num artigo, num livro. Recebem os conhecimentos como se estes nascessem dos toques mágicos de varinhas de condão. [...] É assim a universidade? Se o for, nossa produtividade será marcada pelo número de produtos que arranjamos nas estantes, pelo número de objetos que registramos nos caixas, pelo número de fregueses que saem contentes, pelo número de carrinhos que carregamos até os carros no estacionamento, recebendo até mesmo gorjeta por fazê-lo (CHAUÍ, 2001, p. 112-113).

A partir desse panorama geral sobre as políticas educacionais, principalmente a partir da década de 1990, mediadas por uma agenda neoliberal e um novo modelo de acumulação do capital, percebem-se os desafios para a democratização do acesso à educação superior pública e, numa perspectiva inclusiva, tendo em vista que o Estado convive com uma lógica cada vez mais privatizante, relegando a educação a uma condição de mercadoria, a ser comprada pelos que possuem certo poder aquisitivo.

\section{AÇÕES AFIRMATIVAS COMO POLÍTICAS DE ACESSO}

Como já abordado, a elitização é uma das características mais marcantes da educação superior brasileira. Sua origem está estreitamente ligada à colonização, ao sistema escravocrata e à desigualdade socioeconômica operante na sociedade brasileira. Nesse contexto, as políticas de ações afirmativas foram sendo implantadas como uma forma de democratizar o acesso à educação superior para uma população historicamente excluída dessa modalidade de ensino.

Conforme Silvério (2002, p. 91-92), as ações afirmativas conceituam-se como "um conjunto de ações e orientações do governo para proteger minorias e grupos que tenham sido discriminados no passado. [...] as ações afirmativas têm por objetivo fazer realidade o princípio de igual oportunidade. E [...] prevenir a ocorrência de discriminação". 
A partir da problemática das desigualdades sociais de acesso e permanência da maioria dos jovens brasileiros na educação superior pública, destaca-se que as lutas pela democratização do acesso à educação superior não são recentes, tendo se acentuado a partir dos anos 1980, com o processo de redemocratização do país. As ações afirmativas, ainda que limitadas em seu raio de abrangência e impactos, foram inseridas como políticas públicas específicas para o enfrentamento à elitização do ensino superior brasileiro.

Portanto, um marco legal que fundamentou a temática das ações afirmativas foi a Constituição Federal de 1988, que consolidou o princípio da igualdade perante a lei. Feres Júnior, Daflon e Campos (2012) frisam que, além do importante marco legal introduzido pela Carta Magna com relação à temática racial, é importante destacar como antecedente que marcou a história das ações afirmativas no Brasil a divulgação de análises feitas pelo Instituto de Pesquisa Econômica Aplicada (IPEA) sobre as desigualdades raciais, no final dos anos de 1990. A partir desses estudos, as desigualdades raciais passaram a ter cada vez mais visibilidade governamental e pública, constituindo-se um movimento importante para a consolidação de uma agenda de reivindicações do movimento negro desde a década de 1980.

Em 1999, foi encaminhado ao Congresso Nacional o primeiro Projeto de Lei (PL n ${ }^{\circ} 73 / 99$ ) que dispõe sobre o ingresso de estudantes nas universidades federais, de autoria da deputada Nice Lobão, do Partido da Frente Liberal (PFL). O projeto previa a reserva de 50\% das vagas nas universidades públicas para alunos dos cursos de ensino médio, tendo por base o Coeficiente de Rendimento (CR). Esse PL foi apensado a muitos outros projetos que foram tramitando durante o período de 1999 a 2012, culminando com a aprovação da Lei no 12.711/12.

No ano de 2001, outro marco fundamental para o país adotar políticas de ações afirmativas foi a Conferência Mundial de Combate ao Racismo, Discriminação Racial, Xenofobia e Intolerância, realizada em Durban, na África do Sul. A partir deste marco, o estado brasileiro passou a reconhecer as consequências do racismo e "a necessidade de adoção de medidas que 
pudessem minimizar ou mitigar as consequências dos seus efeitos. Embora a luta pelas Políticas de Ações Afirmativas (PAA) seja antiga [...] foi a partir de Durban que o Brasil passou a experimentá-las de forma mais sistemática" (SANTOS, 2012, p. 289).

A posição do Brasil nesta Conferência foi decisiva para o fortalecimento do debate e para a definição das primeiras experiências de ações afirmativas na educação superior. Além disso, em 2001, o Plano Nacional de Educação (PNE) já estabelecia como meta a ampliação de $12 \%$ para $30 \%$ das matrículas do ensino superior para jovens de 18 a 24 anos (BRASIL, 2001). Essas matrículas deveriam se concentrar em cerca de $40 \%$ no setor público. Esse percentual de $12 \%$ coloca o Brasil numa situação desvantajosa na América Latina, inclusive se comparada com países com situação econômica inferior, como é o caso do Chile, da Argentina, Venezuela e Bolívia (SANTOS; CERQUEIRA, 2009).

$\mathrm{Na}$ sua origem, as ações afirmativas apareceram como cotas ou reserva de vagas nas IES. A partir do ano de 2000, no Estado do Rio de Janeiro, foram aprovadas três leis estaduais ${ }^{1}$ que reservavam vagas para estudantes egressos de escolas públicas, para negros e pessoas com deficiência. Posteriormente, essas leis tiveram reformulações, com inclusão também de indígenas, filhos de policiais militares, civis e agentes penitenciários mortos em serviço (SANTOS, 2012).

A Universidade do Estado do Rio de Janeiro (UERJ) foi a primeira universidade pública a adotar ações afirmativas de caráter social e racial, destinadas a estudantes egressos da escola pública, negros e pessoas com deficiência, o que ocorreu em 2003. A situação gerou muita polêmica, e muitos debates foram realizados naquele período entre a comunidade universitária e também externa. Além disso, motivou duas ações de inconstitucionalidade contra as cotas no Tribunal de Justiça do Rio de Janeiro e, em seguida, ganhou espaço nacional, na instância do Superior Tribunal 
Federal, cujo equacionamento só ocorreu em 2012, quando declarada a constitucionalidade das cotas (SANTOS, 2012).

Ainda, conforme Santos (2012), no mesmo ano, a Universidade Estadual do Norte Fluminense (UNEF) foi a segunda universidade que também aderiu ao sistema de cotas, adequando-se à Legislação Estadual e, embora tenha gerado um certo desconforto, o debate não se estendeu. No Estado da Bahia, a Universidade do Estado da Bahia (UNEB) foi pioneira por implantar um sistema de reserva de vagas para afrodescendentes nos cursos de graduação e pós-graduação de forma autônoma, aprovado em resolução pelo Conselho Universitário, instância máxima da Universidade, também em 2003.

No âmbito federal, a Universidade de Brasília (UnB) foi a primeira universidade federal a adotar ações afirmativas, na qual previu cotas raciais para negros e indígenas e intensificou o apoio ao sistema local de escolas públicas. Conforme destaca Santos (2012), o caso pioneiro da UnB, dentre as universidades federais, foi um processo que se expandiu gradativamente para as demais regiões do país, culminando com a aprovação da Lei $\mathrm{n}^{\circ} 12.711 / 12$. A experiência foi marcada por muito debate, e a reserva de vagas foi realizada por meio de um planejamento interno com respaldo na autonomia universitária, prevista na Constituição Federal e na Lei de Diretrizes e Bases da Educação Nacional (LDBEN) no 9.394/96. As cotas passaram a vigorar em 2004, no segundo vestibular.

A Universidade Estadual de Mato Grosso do Sul (UEMS), também no grupo das pioneiras, aprovou e estabeleceu o sistema de cotas, com a novidade da reserva de vagas de $10 \%$ para indígenas. Assim como nas universidades do Rio de Janeiro, as cotas na UEMS foram motivadas por duas leis estaduais “a Lei no 2.589 , de 26 de dezembro de 2002, estabeleceu a reserva de vagas para indígenas e a Lei $\mathrm{n}^{\circ} 2.605$, de 6 de janeiro de 2003, por seu turno, fixou a reserva de $20 \%$ de vagas para negros" (SANTOS, 2012, p. 302).

Além das iniciativas das próprias universidades, mediante sua autonomia e/ou motivadas por legislações estaduais, algumas ações governamentais 
foram sendo desencadeadas no governo Lula, com vistas à ampliação e democratização do acesso à educação superior.

Uma das primeiras ações do governo Lula para o setor educacional foi a criação de um Grupo de Trabalho (GT) Interministerial, com vistas a analisar a situação daquele momento e apresentar um plano de ação para reestruturação e a democratização das Instituições de Ensino Superior (IFES). A análise realizada pelo GT apontou a desarticulação do setor público brasileiro, uma vez que a prioridade era o setor privado, com uma expansão recorde (SANTOS; CERQUEIRA, 2009).

Outras iniciativas relacionadas ao ensino superior, ainda no ano de 2003, foram a realização de dois seminários. Um deles foi organizado pela Secretaria de Ensino Superior do Ministério da Educação (SESu/MEC), intitulado "Universidade: por que e como reformar". Esse evento fazia um debate preparatório de uma agenda que visava discutir a Universidade do Século XXI. Além disso, o debate situava o surgimento de um novo projeto nacional do governo pautado na expansão do ensino superior e inclusão social (SANTOS, 2003). O outro seminário, de âmbito internacional, foi organizado pelo MEC, com o apoio da UNESCO, do Banco Mundial e da ONG internacional ORUS (Observatorie Internacional des Réformes Universitaires), intitulado: "Universidade XXI: novos caminhos para o ensino superior". Conforme destacam Santos e Cerqueira (2009), os seminários contribuíram para a "redefinição de uma agenda para o ensino superior", servindo de base para o Grupo de Trabalho Interministerial. Os principais temas debatidos e apontados para a Reforma Universitária foram a avaliação e regulação, autonomia acadêmica e financeira, gestão, democratização e o acesso, a estrutura e organização.

Entre os principais desafios relacionados à educação superior foram apontados: "redefinir o seu papel no ensino superior; definir metas claras para o ensino superior; assumir o ensino superior como bem público; realizar uma avaliação criteriosa das IES públicas e privadas; repensar a organização estrutural” (SANTOS, 2003, p. 10). 
No início de 2004, assumiu a pasta no Ministério da Educação o Ministro Tarso Genro, com o propósito prioritário de promover uma Reforma Universitária. Iniciou-se, então, a minuta final do projeto de Lei da Reforma Universitária, PL n 7.200/06 (BRASIL, 2006), que foi encaminhada ao Congresso Nacional em 2006, pelo sucessor de Tarso Genro, Ministro Haddad. O projeto ainda não foi aprovado e continua em tramitação no Congresso Nacional. Na sua origem previa o estabelecimento de normas gerais para a educação superior, a regularização do sistema federal da educação superior e a alteração da Lei de Diretrizes de Bases da Educação Nacional.

Importante destacar que, ainda que a Reforma Universitária não tenha sido aprovada, várias ações foram sendo implementadas pelo MEC, assinalando na prática alguns pontos da reforma. No que tange às ações relacionadas à discriminação racial, destacam-se a criação, em 2003, da Secretaria Especial de Políticas de Promoção da Igualdade Racial (SEPPIR) e a aprovação da Lei no 10.639/2003, "que tornou obrigatória a inclusão da disciplina de história da África e Cultura Afro-Brasileira no currículo de todas as escolas do ensino fundamental" (DAFLON; FERES JÚNIOR; CAMPOS, 2013, p. 403). Nesse sentido, a SEPPIR entende que:

Políticas de reparações e de reconhecimento formarão programas de ações afirmativas, isto é, conjuntos de ações políticas dirigidas à correção de desigualdades raciais e sociais, orientadas para oferta de tratamento diferenciado com vistas a corrigir desvantagens e marginalização criadas e mantidas por estrutura social excludente e discriminatória (MEC/SEPPIR, 2004, p. 12).

O debate das ações afirmativas foi reaquecido em 2004, quando o Presidente Lula apresentou ao Congresso o Projeto de Lei $\mathrm{n}^{\circ} 3.627^{2}$, que previa a reserva de vagas em $50 \%$ para estudantes egressos de escola pública nas Universidades Federais, com vagas específicas para pretos, pardos e indígenas, com base na representação proporcional das etnias nas unidades da

2 O referido PL foi apensado ao PL n 73/99 e a outros PLs, que no ano de 2012 foram transformados na Lei Ordinária $\mathrm{n}^{\circ} 12.711 / 2012$. 
Federação, de acordo com o último censo da Fundação Instituto Brasileiro de Geografia e Estatística (IBGE) (BRASIL, 2004a).

Na mesma ocasião, o governo Lula criou, por meio da Medida Provisória no $213^{3}$, o Programa Universidade Para Todos (PROUNI), que destina bolsas em universidades privadas para estudantes egressos do ensino médio na rede pública ou particular, na condição de bolsista integral, matriculados em IES privadas, para estudantes autodeclarados pretos, pardos e índios e para pessoas com deficiência. O programa foi muito criticado, porém, conforme observam Daflon, Feres Júnior e Campos (2013, p. 404), o PROUNI "representa a principal modalidade de ação afirmativa aplicada ao ensino superior privado, sendo a política de maior impacto".

No ano de 2007 foi lançado o Plano de Desenvolvimento da Educação (PDE) em que o governo propõe uma série de medidas para as instituições educacionais de todos os níveis (SEVERINO, 2008). Na educação superior situam-se duas metas principais: "a ampliação do acesso e a articulação entre os programas de financiamento do ensino superior" (SEVERINO, 2008, p. 82). A finalidade é a ampliação de cursos noturnos nas Universidades Federais e dobrar o número de vagas, além de uma articulação entre o Fundo de Financiamento Estudantil (FIES) e o PROUNI.

Ainda no ano de 2007, como uma das ações que integram o PDE/2007, foi instituído, por meio do Decreto no 6.096/2007, o Programa de Apoio a Planos de Reestruturação e Expansão das Universidades Federais (REUNI), com o principal objetivo de ampliar o acesso e a permanência na educação superior. A partir do REUNI, o governo federal adotou uma série de medidas para retomar o crescimento do ensino superior público, buscando viabilizar condições para que as universidades pudessem promover com qualidade a expansão física, acadêmica e pedagógica da rede federal de educação superior.

Também se destaca o Programa Nacional de Assistência Estudantil (PNAES), criado em 2008 pelo Ministério da Educação e regulamentado em 2010 , por meio do Decreto $n^{\circ} 7.234$. O programa objetiva apoiar a permanência

3 Em 2005 foi convertida na Lei $n^{\circ}$ 11.096/05. 
de estudantes em situação de vulnerabilidade socioeconômica em cursos de graduação nas Instituições Federais de Ensino Superior (BRASIL, 2010a).

O Exame Nacional do Ensino Médio (ENEM), criado ainda no ano de 1998, passou a ser utilizado, a partir de 2009, como mecanismo para avaliar o desempenho dos estudantes para a seleção em cursos de graduação, sendo adotado por muitas IFES como etapa única ou parcial (SANTOS; CERQUEIRA, 2009).

Nesse cenário, caracterizado por muitas políticas destinadas à interiorização e à democratização do acesso e da permanência à educação superior, como o REUNI, PROUNI, PNAES, FIES, ENEM, constatou-se que houve um crescimento das matrículas na educação superior, aumentando o número de brasileiros com acesso a esse nível de ensino. Conforme dados do MEC/ INEP (2014a), em 2012, quase 30\% das pessoas, em relação à população de 18 a 24 anos, tinha acesso à educação superior. A taxa de escolarização bruta na educação superior passou de 16,6\%, em 2002, para 28,7\%, em 2012.

Gráfico 1 - Evolução da taxa bruta de escolarização na Educação Superior no Brasil (1960-2012)

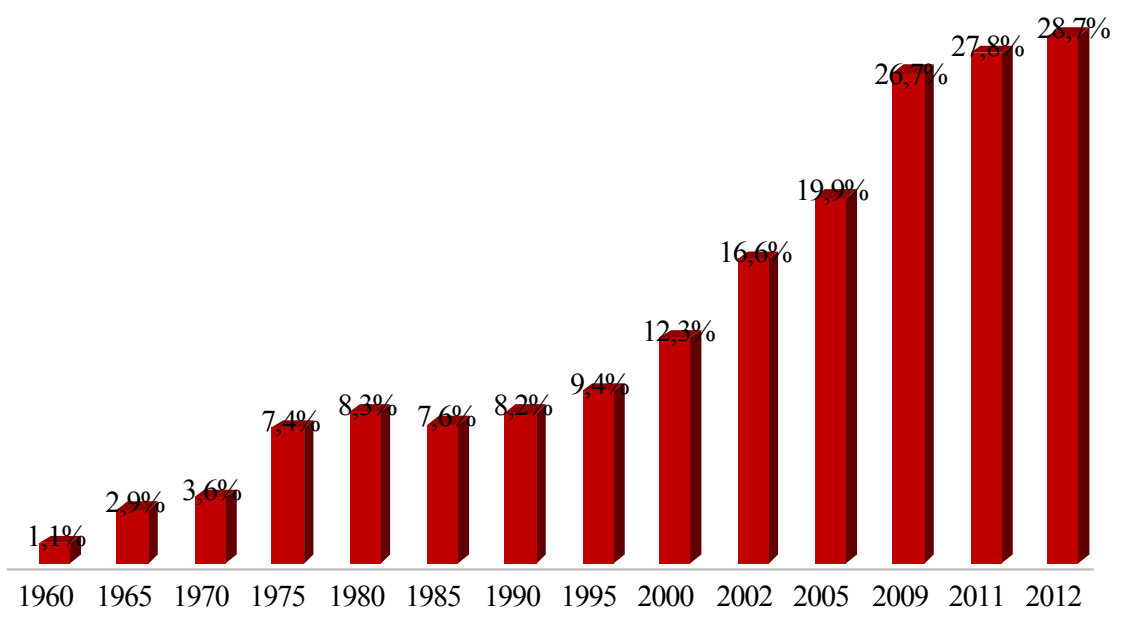

Fonte: MEC/INEP (2013b; 2014a). 
Ao considerar as regiões geográficas, em 2012, a Região Sul apresenta uma taxa bruta de $34,5 \%$, taxa líquida de $19,8 \%$ e uma taxa líquida ajustada de 25,0\%. Esses percentuais ficam acima da média brasileira e, se comparada com as demais regiões, a Região Sul apresenta as melhores taxas líquidas, ou seja, possui um número maior de pessoas cursando ou que já concluíram a Educação Superior na faixa etária de 18 a 24 anos (MEC/INEP, 2014a).

Ainda, considerando o período de cinco décadas na história da educação superior brasileira, a tabela 1 apresenta a evolução do número das instituições, cursos e de concluintes, nesse período.

Tabela 1 - Número de IES, cursos e concluintes na educação superior do Brasil (1968-2012)

\begin{tabular}{l|l|l|l}
\hline Ano & Instituições & Cursos & Concluintes \\
\hline 1968 & 779 & 1.712 & 42.550 \\
\hline 1975 & 860 & 3.497 & 161.183 \\
\hline 1985 & 859 & 3.923 & 234.173 \\
\hline 1995 & 894 & 6.652 & 254.401 \\
\hline 2005 & 2.165 & 20.596 & 730.484 \\
\hline 2012 & 2.416 & 31.866 & 1.050 .413 \\
\hline
\end{tabular}

Fonte: MEC/INEP (2013b).

Conforme sinaliza o MEC/INEP (2014a), a maioria das IES, representada por $65,0 \%$, encontra-se localizada em municípios do interior. A Região Sul concentra um percentual de 74,3\%. Juntas, Região Sul e Região Sudeste, tem um percentual de $73,7 \%$, com o maior número de IES do país, ditando a tendência nacional. Existe uma diferenciação entre as regiões, pois na Região Norte, por exemplo, a maioria das IES está situada nas capitais; apenas $38,3 \%$ no interior.

Outra característica da educação superior é a oferta dos cursos nas Instituições privadas. Em 2012, com base no MEC/INEP (2013b, p. 19), “das 2.416 instituições de educação superior do Brasil, apenas $8 \%$ são Universidades e detêm mais de $54 \%$ dos alunos, são, portanto, grandes 
instituições. Por outro lado, as faculdades têm uma participação superior a $84 \%$, mas atendem pouco menos de $29 \%$ dos alunos".

Dessa forma, das 7.037.688 matrículas realizadas na educação superior, em 2012, a maioria está concentrada em universidades, 54,2\%; em faculdades, 28,8\%; em centros universitários, $15,4 \%$; e em institutos federais (IFs e Cefets), 1,6\%. Naquele ano registrou-se 73,0\% das matrículas na rede privada, das quais $15,5 \%$ estavam distribuídas nas IES da rede federal; 9,9\% nas IES da rede estadual; e 2,6\% nas IES municipais (MEC/ INEP, 2014a). Pela análise do gráfico 2, que demonstra a evolução das matrículas no período de 2003 a 2012, conforme a categoria administrativa, constatou-se que o aumento do número de matrículas ocorreu principalmente no âmbito privado.

Gráfico 2 - Evolução do percentual de matrículas na educação superior no Brasil (2003-2012)

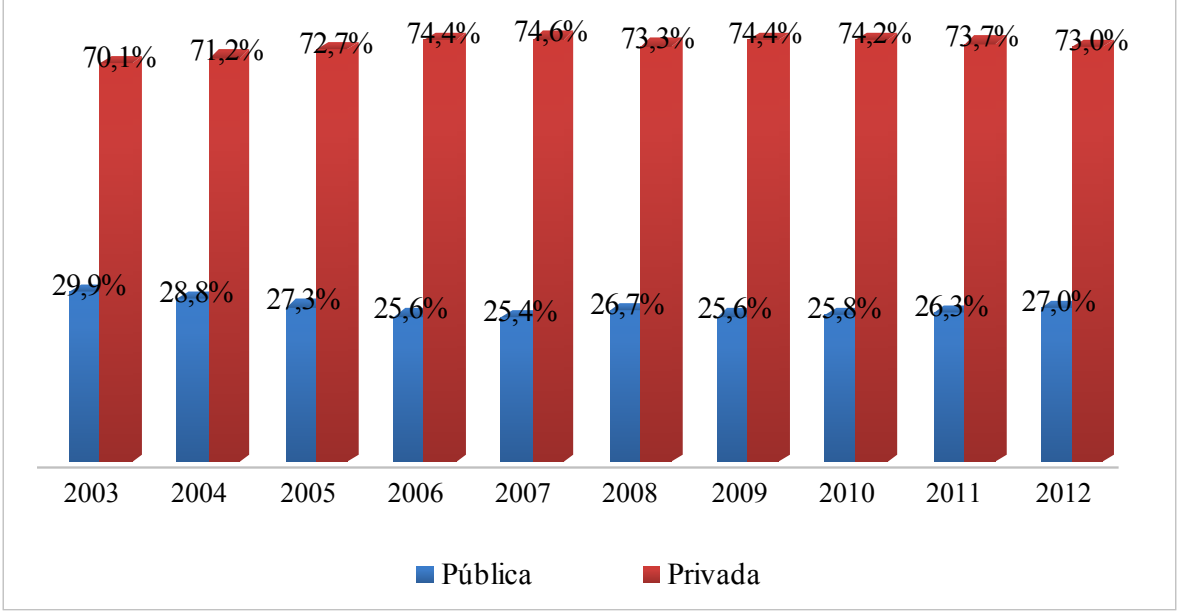

Fonte: Elaboração própria com base em MEC/INEP (2014a).

Com relação ao crescente aumento de matrículas nas IES privadas, Giolo (2009) destaca que essa situação não é tão recente e remete ao ano de 1996, principalmente, quando foi aprovada a nova Lei de Diretrizes e Bases (LDB). Essa legislação educacional permitiu uma maior flexibilização 
para a educação superior, a diversificação das formas de oferta, das IES e dos cursos. Para muitos organismos, essa situação remetia a uma forma de melhorar os índices da educação e, para muitos investidores, uma forma de tornar a educação um negócio, um bem comerciável e lucrativo.

As instituições públicas que não foram privatizadas experimentaram um interminável calvário, como foi o caso das instituições educacionais, e as instituições privadas gozaram de muito crédito (nos dois sentidos: moral e financeiro) e muito estímulo. A LDB é a expressão desse momento e desse contexto e acabou sendo decisiva para a criação do mercado educacional referido aqui. O teste da realidade a princípio confirmou a regra: os indicadores mostravam que, em todos os lugares, as instituições de educação superior se instalavam e prosperavam (GIOLO, 2009, p. 3).

Ainda conforme o autor, várias foram as estratégias utilizadas pela rede privada para a expansão da educação superior: educação a distância, oferta de cursos no interior e com menores custos, oferta de cursos voltados para a tecnologia, com vistas a atender rápido ao mercado de trabalho. A título de exemplo, no período de 1996 a 2007, enquanto as instituições públicas cresceram $18,0 \%$, as instituições privadas cresceram a uma taxa de 185,8\%, passando, estas últimas de 711 IES, em 1996, para 2.032, em 2007, e de 3.666 cursos para 16.892 (GIOLO, 2009).

Com essa expressiva expansão da educação superior, principalmente na rede privada, reforçam-se os desafios pela democratização do acesso às camadas populares. Para Giolo (2009, p. 13):

A expansão do ensino em direção às classes populares terá de contar com uma decisiva ação do poder público, em primeiro lugar, para expandir o ensino médio e, em segundo lugar, para dar oportunidades em instituições públicas aos alunos das classes populares que quiserem realizar sua formação em nível superior. Já não se pode fazer, no Brasil, expansão sem democratização, pois os dois processos se tornaram interdependentes de forma absoluta. As instituições públicas, além de serem ampliadas (em novos campi e novas 
instituições) precisam atuar com mais firmeza na implantação de uma política de cotas e na abertura de cursos noturnos.

Para Ristoff (2013a), predominou, ao longo de mais de vinte anos, uma política nacional privatizante na educação superior, com uma lógica de expansão pelo viés da participação do setor privado. Somente a partir de 2006, constataram-se indícios de contenção dessa expansão por meio de políticas estimuladoras à recuperação das instituições federais públicas. Para o autor, em 2010 e 2011 o crescimento do setor público começa a ter números mais expressivos, com um ritmo ligeiramente superior ao apresentado pelo setor privado.

A partir desse cenário, que caracteriza a educação superior, situa-se uma das políticas mais recentes, que após muita pressão por parte dos movimentos sociais, torna-se uma realidade, a "Lei das Cotas". Trata-se de mais uma política pública que tem por finalidade contribuir para o processo da democratização da educação superior.

\section{“LEI DAS COTAS” E DEMOCRATIZAÇÃO}

Durante os treze anos de tramitação do Projeto de Lei, que culminou com a "Lei das Cotas", destacam-se a importância das primeiras experiências nas universidades com a adoção de ações afirmativas e o papel dos movimentos sociais, principalmente do Movimento Negro, para que essas políticas pudessem de fato democratizar as condições para o acesso e a permanência na Educação Superior. Por outro lado, esse debate sempre foi muito polêmico, marcado por muitos movimentos de resistência às cotas, principalmente as de caráter étnico.

Situa-se, como um movimento de resistência às cotas, o Manifesto “Todos têm direitos iguais na República Democrática - posicionamento de intelectuais brasileiros contra o sistema de cotas raciais" ${ }^{4}$. Esse manifesto 
foi assinado por alguns intelectuais brasileiros e foi encaminhado, em 29 de junho de 2006, ao Congresso Nacional, aos deputados e senadores, com pedido, em nome da República Democrática, que recusassem o PL $\mathrm{n}^{\circ} 73 / 1999$ (PL das Cotas) e o PL n 3.198/2000 (PL do Estatuto da Igualdade Racial).

Em seguida ocorre uma reação por parte de grupos favoráveis à adoção de cotas raciais nas universidades e, em 04 de julho de 2006, é apresentado ao Congresso Nacional o Manifesto "Em favor da Lei de Cotas e do Estatuto da Igualdade Racial ${ }^{\text {". }}$ O documento conclamava aos congressistas a aprovação da "Lei de Cotas" (PL 73/1999) e o Estatuto da Igualdade Racial (PL 3.198/2000).

Ao mesmo tempo em que essas manifestações estavam acontecendo, tramitavam no Supremo Tribunal Federal duas ações de inconstitucionalidade. Uma delas era a Ação Direta de Inconstitucionalidade, ADI n ${ }^{\circ}$ 3.330, ajuizada em 2004, que questionava o PROUNI, cuja proposição foi feita pela Confederação Nacional dos Estabelecimentos de Ensino (CONFENEN), pela Federação Nacional dos Auditores Fiscais da Previdência Social (FENAFISP) e pelo Partido dos Democratas (DEM). Outra ação, também movida pela CONFENEN, era a ADI no 3.197, contra o sistema de cotas implantado nos concursos vestibulares para o ingresso de candidatos ao ensino superior das universidades estaduais do Rio de Janeiro.

Em 2008, mais dois manifestos foram entregues ao então Presidente do Supremo Tribunal Federal, Ministro Gilmar Mendes. Um deles, entregue em abril de 2008, declarava-se contra as leis raciais, o Manifesto "Cento e treze cidadãos antirracistas contra as leis raciais". O teor desse documento aprofundava o manifesto anterior e questionava a constitucionalidade das cotas.

O outro Manifesto foi encaminhado ao Supremo Tribunal Federal, em maio de 2008, por um grupo de estudantes, artistas e ativistas de direitos

\footnotetext{
5 Disponível em: <http://www.observa.ifcs.ufrj.br/manifesto/index.htm>. Acesso em: 21 fev. 2014.

6 Disponível em: <http://revistaepoca.globo.com/Revista/Epoca/0,EDR83466-6014,00.html>. Acesso em: 21 fev. 2014.
} 
humanos, em resposta aos manifestos anteriores. O Manifesto " 120 anos da luta pela igualdade racial no Brasil. Manifesto em defesa da Justiça e constitucionalidade das cotas"7 apresentava os avanços já conquistados por meio das ações afirmativas e a defesa do projeto de "Lei das Cotas" e do Programa PROUNI. Também trazia críticas aos manifestos anteriores de reação às cotas, mais especificamente para negros. Destaca-se o importante papel da sociedade civil organizada nesse processo, pois consta no Manifesto que "a difusão das ações afirmativas é fruto de uma luta histórica e uma extraordinária mobilização social que produziu uma efervescência de debates em ambientes políticos e acadêmicos em todas as regiões do país" (NASCIMENTO et al., 2008, p. 4).

No ano de 2009, o partido Democrata entrou com mais uma ação no Supremo Tribunal Federal, a Arguição de Descumprimento de Preceito Fundamental, ADPF $\mathrm{n}^{\circ} 186$, que questionava o sistema de cotas adotado pela Universidade de Brasília (UnB), que destinava 20\% de suas vagas para negros. Também a ação pedia a extensão da decisão a todos os programas desta natureza do país (FERES JÚNIOR; DAFLON; CAMPOS, 2013).

Em julho de 2010, foi aprovada a Lei no 12.288 que dispõe sobre o Estatuto da Igualdade Racial. Este Estatuto prevê a efetivação da igualdade de oportunidades à população negra, e uma das medidas para esse fim foi a adoção dos programas de ações afirmativas por parte do poder público. Para Daflon, Feres Júnior e Campos (2013, p. 406) o Estatuto “oficialmente reconheceu o Brasil como um país multirracial e multiétnico no qual as pessoas de descendência africana estiveram sujeitas à discriminação racial".

Em 2012, após um longo tempo de tramitação, foram julgadas as ações de inconstitucionalidade contra as cotas (ADI no 3.197) e contra o programa PROUNI (ADI no 3.330). Na primeira delas, o Supremo Tribunal Federal julgou a constitucionalidade das cotas nas universidades estaduais do Rio de Janeiro; a segunda, ADI n 3.330, também foi julgada

7 Disponível em: <http://www.cefetsp.br/edu/eso/culturainformacao/manifesto_favor_cotas.pdf $>$. Acesso em: 21 fev. 2014. 
pela constitucionalidade, tendo a maioria dos votos do Plenário do Supremo Tribunal Federal.

A ADPF $\mathrm{n}^{\circ} 186$ foi direcionada para a instância mais alta do país, para o Ministro do Superior Tribunal Federal: Enrique Ricardo Lewandowski. Em abril de 2012, após dois dias de julgamento, a Suprema Corte votou declarando a constitucionalidade da política de cotas e julgou improcedente a ação impetrada pelo partido Democrata, concluindo pela constitucionalidade da política de cotas adotada pela Universidade de Brasília (UnB).

De 1999 até 2012 também foram realizados diversos seminários e centenas de audiências públicas, atividades sempre marcadas pela pluralidade de visões sobre os efeitos e o mérito do projeto e, após 13 anos de tramitação no Congresso Nacional, decidiu-se pela constitucionalidade das cotas e do PROUNI. Meses depois, em outubro de 2012, a Presidenta Dilma sancionou a Lei no 12.711 , conhecida como a "Lei das Cotas", que foi em seguida regulamentada pelo Decreto ${ }^{\circ} 7.824$ e pela Portaria MEC $n^{\circ} 18$.

É importante destacar que até a aprovação da Lei no 12.711 as ações afirmativas foram sendo implementadas nas instituições de diversas formas. A partir de um levantamento realizado em 70 instituições de ensino superior público, que adotavam algum tipo de ação afirmativa, no período de 2002 a 2010, Feres Júnior, Daflon e Campos (2013) apontam que a cota era a modalidade mais comum, mas apareciam outras formas como bônus e acréscimo de vagas. No período em destaque as ações afirmativas se faziam presentes em mais de $70 \%$ das instituições de ensino superior públicas no país, e a maioria dessas universidades foi operando com legislações próprias, como resoluções universitárias e leis estaduais.

Quanto às modalidades de ação afirmativa, os autores situam que a mais praticada é a que beneficia estudantes oriundos de escola pública, sendo esta referenciada como uma ação afirmativa social. Cerca de $87,1 \%$ dos beneficiários de ações afirmativas são alunos de escola pública, em seguida aparecem os negros, representando $57,1 \%$, e os indígenas, $51,4 \%$, seguidos de outras modalidades como pessoas com deficiência, quilombolas, baixa 
renda, entre outras. Consideram ser esta uma distorção do debate público sobre o tema, pois "programas que utilizam categorias étnicas raciais não são sequer os mais comuns entre as modalidades de ação afirmativa no ensino superior público de nosso país" (FERES JÚNIOR; DAFLON; CAMPOS, 2013, p. 4).

Conforme Cara (2012, p. 11), “a sociedade civil organizada venceu os debates no Congresso Nacional, em alguns momentos contra as posições do Governo [...] porque acumulou mais argumentos técnicos e soube somar a eles uma eficaz mobilização social, fortalecida por incansável pressão política”.

A "Lei das Cotas" constituiu um marco para a educação superior pública brasileira e, com a sua aprovação, os institutos técnicos federais e as universidades públicas federais passaram a ser obrigadas a reservar, no quadro de suas vagas, 50\% para estudantes que cursaram integralmente na rede pública o ensino médio, para o acesso às universidades federais, e o Ensino Fundamental para o acesso aos Institutos Federais (BRASIL, 2012a).

No preenchimento das vagas devem ser reservadas $50 \%$ (cinquenta por cento) aos estudantes oriundos de famílias com renda per capita igual ou inferior a 1,5 salários-mínimos (um salário-mínimo e meio) e, com distribuição proporcional, deverão ser preenchidas vagas por curso e por turno pelos estudantes autodeclarados pretos, pardos e indígenas, com referência na população da unidade da Federação onde está instalada a instituição, conforme o último censo do Instituto Brasileiro de Geografia e Estatística (BRASIL, 2012a).

A figura 1 representa a distribuição de vagas a partir da nova Lei. 
Figura 1 - Distribuição de vagas conforme a Lei no $12.711 / 12$

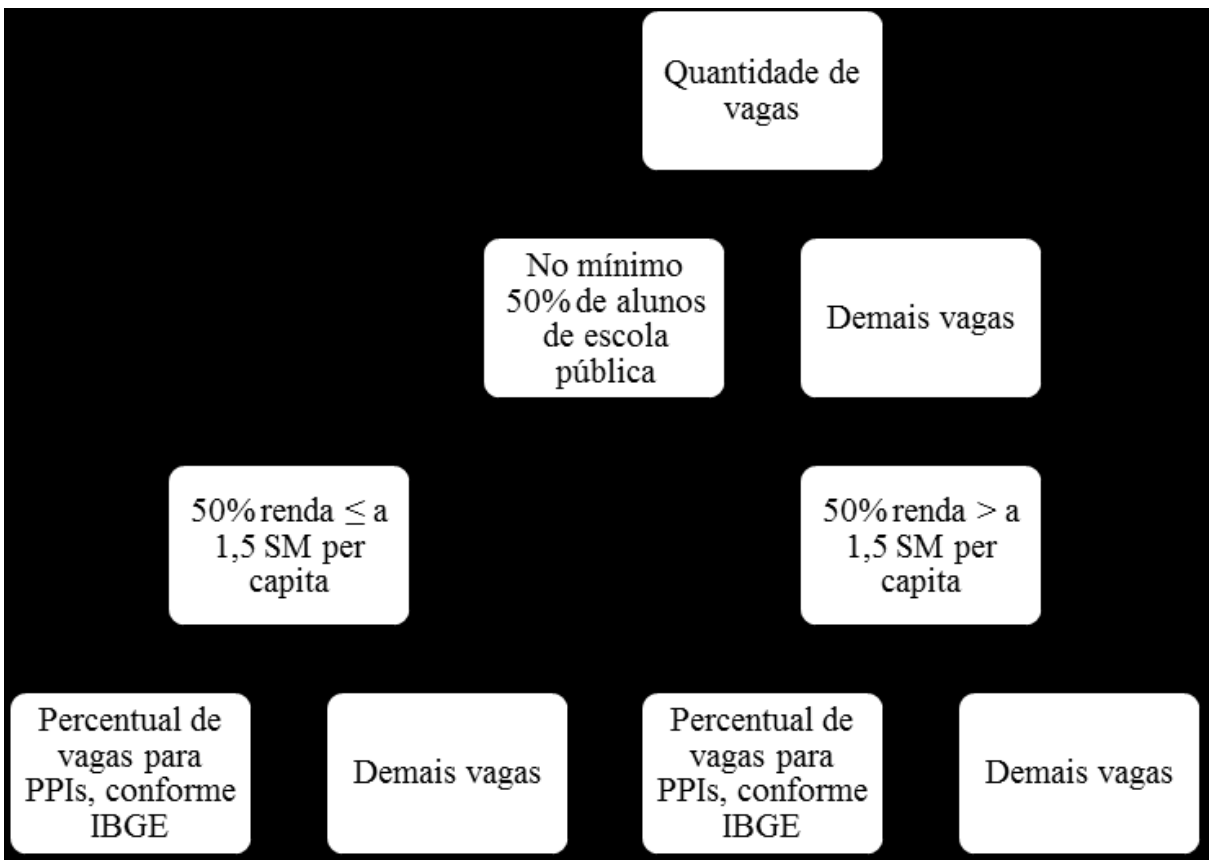

Fonte: Lei $\mathrm{n}^{\circ} 12.711 / 12$.

Nota: $\mathrm{SM}=$ salário-mínimo; PPIs = pretos, pardos e índios

A “Lei das Cotas" tem a previsão de ser avaliada no período de dez anos, porém o debate e as polêmicas continuarão, principalmente com relação à sua aplicação e efetividade. Porém, há de se destacar que está em curso uma mudança no perfil dos estudantes das universidades públicas brasileiras e a lei veio com a expectativa da uniformização dessas iniciativas em todo o país.

Em relação ao significado dessa política para a educação brasileira, Santos (2012, p. 307) reconhece: "trata-se de um marco histórico, pois reflete um compromisso explícito do Estado Brasileiro com segmentos historicamente excluídos desse importante lugar social que é a universidade pública”. A despeito da importância da referida lei para a democratização do acesso ao ensino superior, ela não é suficiente para dar conta da redução 
das grandes desigualdades existentes. Aponta-se, por exemplo, a necessidade de uma consistente política de permanência para os estudantes.

Santos (2012, p. 306) observa que a "[...] luta e o combate a todo tipo de discriminação, melhoria na distribuição da renda, entre outros, são mecanismos indispensáveis à promoção da verdadeira inclusão". O autor sinaliza, ainda, que se fazem pertinentes outras medidas com vistas à democratização de todo o sistema educacional, como a melhoria de educação básica pública como um todo, principalmente o ensino médio.

Para Dourado (2012, p. 11), essa lei representa um passo importante para democratizar o acesso ao ensino superior e "ao estabelecer cotas de $50 \%$ para estudantes da escola pública, resgata uma dívida histórica do Estado brasileiro e sua efetivação certamente contribuirá para o estabelecimento de vínculo mais orgânico entre as instituições públicas de educação básica e as de ensino superior".

Oliveira (2012) considera que, por muitos séculos, se convive no Brasil com um sistema educacional precário, organizado de forma fragmentada, dualista e seletivo, e a aprovação da "Lei das Cotas" tem o grande desafio de repensar toda a estrutura da educação superior pública brasileira, assegurando a sua qualidade e o seu caráter democrático, como um bem público de acesso a todos os brasileiros.

Feres Júnior, Daflon e Campos (2012, p. 413) apontam que as políticas de ações afirmativas "[...] que atendem tanto o critério classe social (via o critério escola pública) como raça, estão mudando a face da educação superior em nosso país, pelo menos no que toca ao acesso a instituições de ensino de qualidade, caso das universidades públicas".

Destaca-se que os desafios para a universalização do acesso à educação superior no Brasil são grandes, pois chama a atenção a quantidade de jovens que ainda se encontram fora das instituições educacionais. Os dados apontados por Carvalhaes, Feres Júnior e Daflon (2013) demonstram o desafio de acesso dos jovens à educação superior, pois cerca de 20\%, em média, dos jovens na faixa etária de 15 a 17 anos, não estão frequentando a 
escola. $\mathrm{O}$ ensino médio, portanto, constitui um grande obstáculo de retenção. Segundo afirma o IBGE (2013a, p. 123), “em 10 anos, a proporção de jovens de 15 a 17 anos de idade que frequentavam escola cresceu somente 2,7 pontos percentuais, passando de $81,5 \%$, em 2002 , para $84,2 \%$, em 2012 ".

A “Lei das Cotas" está nos primeiros anos de implementação, e os seus resultados ainda precisam ser avaliados. Ao realizar um estudo comparativo dos percentuais de vagas que deveriam ser reservadas nas universidades e o que ocorre de fato, no primeiro ano de aplicação da referida Lei, Feres Júnior et al. (2013, p. 26) observam que "as universidades ainda não estão cumprindo a lei em sua integralidade, o que deve ser reflexo da sua implantação gradual. O percentual total de vagas reservadas em todas as federais - 31,5\% - ainda está aquém dos 50\% estabelecidos pela Lei $\mathrm{n}^{\circ} 12.711^{\prime \prime}$.

Verificaram-se muitos programas e ações por parte dos governos na tentativa de ampliar o número de matrículas na educação superior pública, tendo em vista um contexto de forte privatização e elitização presentes até então. Ao realizar essa contextualização, é possível apontar algumas conquistas, contudo, indica-se que muitos são os avanços que precisam acontecer para uma educação de qualidade, pública e universal. Destaca-se, ainda, que não se pode esquecer a herança histórica que marcou a educação brasileira, com uma educação elitizada, com marcas de profundas desigualdades sociais e raciais.

Por fim, considera-se que as ações afirmativas no âmbito do ensino superior brasileiro encontraram um campo político fecundo para seu desenvolvimento nesses últimos anos. No entanto, cabe destacar que se trata de uma luta histórica, também de movimentos sociais e outras instâncias da sociedade civil, pela democratização das condições de acesso das camadas mais pobres à educação superior, tendo em vista a longa trajetória da elitização desta modalidade de ensino. 